\title{
Is there an association between gender and surgical output in university of port harcourt teaching hospital?
}

\begin{abstract}
Aim: To find out the association between gender and cataract, Trabeculectomy, corneal and squint surgery surgical output in University of Port Harcourt Teaching Hospital

Method: The ophthalmic clinical/surgical database of the university of Port Harcourt Teaching hospital (UPTH) was retrospectively reviewed over a 5-year period to obtain information on the patients' demographics, clinical features, and indications for surgery, type and date of surgery. The data obtained was entered into Epi Info statistical software, version 16 and analyzed after the data entry was validated by double entry. Descriptive statistics was used to yield frequencies, percentages and proportions. Analytical statistics was by chi-square test and a p value $<0.05$ was considered statistically significant. The demographics of patients, the output, and types of ophthalmic surgeries were assessed.

Results: Of all the patients who had surgical related cases, 51.4\% were males while $48.5 \%$ were females. However of the total that eventually had surgery, $58 \%$ were males while $42 \%$ were females. This clearly showed that the variation in gender with respect to case presentation was insignificant, however more males presented for surgery in an approximate ratio of $3: 2$. Of all males that presented $34.4 \%$ had surgery while only $26.3 \%$ of females were operated upon.

Conclusion: Though an approximate equal number of males and females presented with ophthalmic surgical related cases, more males actually had surgery than females in an approximate ratio of 3:2. Reasons for this could be attributed to the late presentation, proximity to health facility and probably seasonal variation in patients turn over as a result of farming exercise.
\end{abstract}

Keywords: cataract, trabeculectomy, cornea, squint, gender
Volume 7 Issue 2 - 2017

\author{
AO Adio,' Chinawa NE, ${ }^{2}$ Chukwuka IO,' \\ Anyiam FE ${ }^{3}$ \\ 'Department of Ophthalmology, University of Port Harcourt \\ teaching Hospital, Nigeria \\ ${ }^{2}$ University of Uyo Teaching Hospital,Akwaibom State/Siloam \\ Eye Foundation, Nigeria \\ ${ }^{3}$ Centre for Health \& Development, University of Port Harcourt, \\ Port Harcourt, Nigeria
}

Correspondence: AO Adio, Department of Ophthalmology, University of Port Harcourt teaching Hospital, Rivers state, Nigeria,Email drdayoadio@yahoo.com

Received: June 12, 2017 | Published: July 13, 2017

\section{Introduction}

The art of Surgery, over the years has taken a dramatic and eventful turnaround with the advent of cutting edge technology. This has necessitated the emergence of new equipment and the need to acquire new skills to keep up with ever improving modernization. Ophthalmic surgery was not left behind with great improvements in the technique and outcome of common surgeries like cataract, trabeculectomy, corneal and squint surgeries etc. Even with improved technique and better skills, patients surgical turn over still remain disappointing, particularly in teaching hospitals as evidenced by records in the log books in the theater. This could possibly be attributed to socioeconomic factors, poor awareness, gender etc. ${ }^{1}$ Women make up $50 \%$ of population and $70 \%$ of the poor. ${ }^{2}$ It has been observed that there are more blind women than men. Women are $1.43 \%$ times more likely to be blind than men. ${ }^{3}$ Also women are at a higher risk of acquiring diseases that can lead to blindness. ${ }^{4}$ In addition, in least developed countries, women utilize eye care services less frequently than men. ${ }^{5}$ Women disproportionately bear the burden of health inequalities across the globe and face unique barriers in accessing medical care. Not only are women more likely to have higher rates of blindness, they are also less likely to obtain proper eye care.

Gender in particular has been a topical issue in recent times, in terms of number blind, number not accessing services, number actually being operated upon, number being visually rehabilitated, number being integrated back into the communities and being empowered economically to contribute their quota etc. In terms of gender roles and in many ways, the lives of women and men have become more similar, as more and more women have entered the labour market. Despite this, differences remain. Although the pay gap has narrowed, women still earn less than men and follow very different career paths in some cases. Furthermore, the majority of the responsibility for household chores and childcare is still the province of women whether they work or not. Studies have shown that women can expect to live longer than men but these extra years of life may not be years of healthy life. ${ }^{6}$ In the course of carrying out our duties, it has been noted that more males than females are admitted into the ward for surgery. This study is carried out to determine objectively if indeed this was so and adduce possible reasons for this and proffer a way or ways to achieve a balance.

\section{Materials and methods}

The ophthalmic clinical/surgical database of the university of Port Harcourt Teaching hospital (UPTH) was retrospectively reviewed over a 5-year period to obtain information on the patients' demographics, clinical features, and indications for surgery, type and date of surgery. The data obtained was entered into Epi Info statistical 
software, version 16 and analyzed after the data entry was validated by double entry. Descriptive statistics was used to yield frequencies, percentages and proportions. Analytical statistics was by chi-square test and a $\mathrm{p}$ value $<0.05$ was considered statistically significant. The demographics of patients, the output, and types of ophthalmic surgeries were assessed. The number of patients diagnosed to have ocular surgical related cases and the number of those who eventually underwent surgery within the aforementioned period were noted. Gender differences in association with surgical case presentation and actual surgery were assessed and such factors such as age, occupation, geographical location and time of the year in relation to patients' presentation were also assessed.

\section{Results}

The total number of patients who presented to the clinic within the five-year period (2006-2010) was noted to be 1378(males:709, Females:669). Out of these number, 420 (male 244 and Females
263) had surgeries giving a percentage surgical turnover of $34.4 \%$ of males and $26.3 \%$ of females ie (number that had surgery/number that presented in clinic with surgical case). The ratio of the males who presented is approximately equal to that of the females (1:1) but more males actually had surgery in the approximate ratio of $3: 2$. This is represented in the Table $1.1 \& 1.2$. In finding out the factors responsible for this variation, the impact of time/age of presentation was considered. Of all the females who presented at the eye clinic, $30 \%$ were elderly while $35.4 \%$ were middle age. However the eventual turn out for surgery was majorly elderly $(33.7 \%)$ which constitutes the highest percentage as against $50 \%$ young adults who had surgery for males $(\mathrm{p}=0.00)$. This showed that older women presented as opposed to men who presented earlier. The fact that a very large percentage of elderly women presented and also went ahead to have surgery, showed they had operable cataract at presentation at that age as compared to $10 \%$ of elderly males who had surgery from the $28.4 \%$ that presented see Table $2.1 \& 2.2$

Table I.I Analysis diagnosis by sex distribution

\begin{tabular}{llllll}
\hline Parameters & Sex & & Total & X2 & p-value \\
\cline { 2 - 6 } & $\begin{array}{l}\text { Male } \\
\text { freq (\%) }\end{array}$ & $\begin{array}{l}\text { Female } \\
\text { freq (\%) }\end{array}$ & & & \\
\hline Diagnosed & $709(51.5)$ & $669(48.5 \%)$ & $1378(100.0)$ & 2.56 & $0.109 *$ \\
\hline
\end{tabular}

*Not Significant $(p>0.05)$

Table 1.2 Ocular surgery by sex distribution

\begin{tabular}{llllll}
\hline Parameters & Sex & & Total & X2 & p-value \\
\cline { 2 - 6 } & $\begin{array}{l}\text { Male } \\
\text { freq (\%) }\end{array}$ & $\begin{array}{l}\text { Female } \\
\text { freq (\%) }\end{array}$ & & & \\
\hline Operated & $244(58.10)$ & $176(41.90)$ & $420(100.0)$ & 22.02 & $0.00^{*}$ \\
\hline
\end{tabular}

*Significant $(p<0.05)$

Table 2.I Age range by sex distribution of diagnosed cases

\begin{tabular}{lllll}
\hline \multirow{2}{*}{ Age Range } & \multicolumn{2}{l}{ Sex } & \multirow{2}{*}{ X2 } & \multirow{2}{*}{ p-value } \\
\cline { 2 - 3 } & Male (\%) & Female (\%) & & \\
\hline Children (<20 years) & 17 & 30 & 64.71 & $0.00 *$ \\
Young Adult (20-44 years) & 27 & 35.5 & 23.12 & $0.00^{*}$ \\
Middle Aged (45-64) & 26.6 & 20 & 16.8 & $0.00^{*}$ \\
Elderly (>64) & 29.4 & 14.5 & 89 & $0.00 *$ \\
\hline
\end{tabular}

*Significant $(p<0.05)$

Table 2.2 Age Range by sex distribution of those that had surgery

\begin{tabular}{lllll}
\hline Age Range & \multicolumn{2}{l}{ Sex } & X2 & P-value \\
\cline { 2 - 3 } & Male (\%) & Female (\%) & & \\
\hline Children (<20 years) & 20.4 & 16.7 & 2.02 & 0.155 \\
Young Adult (20-44 years) & 49.6 & 20 & 80.72 & $0.00 *$ \\
Middle Aged (45-64) & 20 & 29.6 & 10.22 & $0.00^{*}$ \\
Elderly (>64) & 10 & 33.7 & 69.59 & $0.00^{*}$ \\
\hline
\end{tabular}

*Significant $(p<0.05)$ 
The patient's proximity to the hospital was considered. Of the male population who presented, 454 were urban dwellers and thus closer to the base hospital while 255 were rural dwellers. 153 operated males were urban dwellers while 91 were rural dwellers. However, 437 females who presented were urban dwellers while 232 were rural dwellers. Of those that had surgeries, 121 were urban -based while 55 are from rural area. Taking the total therefore shows that of all that presented, $891(65 \%)$ were from urban area while $487(35 \%)$ were from rural area. This is reflected directly on the 274(65\%) from urban area who had surgery and $146(35 \%)$ from rural area who had surgery. Of all that had surgery from urban area statistically significant number of male compared to female had surgery $(\mathrm{p}=0.01)$. This was also the case among rural dwellers who had surgery as statistically significant more males had surgery $(\mathrm{p}=0.00)$.

Table 3.I Location by sex distribution of all diagnosed cases
In our study approximate equal percentage $(35 \%)$ of males and females were rural dwellers, however slightly fewer percentage of female $(32 \%)$ who had surgery were from the rural area as opposed to $38 \%$ of male who had surgery. See Table $3.1 \& 3.2$. . The effect of the time of the year was considered by taking the percentage presentation and surgery at three-monthly intervals. The least case presentation was between April and June for both gender; 15\% for male and 12.9\% for females. However this period had the highest percentage surgery of $56 \%$ for male and $47 \%$ for female. On a general note, highest surgical output for both genders was $32.7 \%$ for male and 31.75 for females between October and December see Table $4.1 \& 4.2$.

\begin{tabular}{|c|c|c|c|c|c|}
\hline \multirow[t]{2}{*}{ Location } & \multicolumn{2}{|l|}{ Sex } & \multirow[t]{2}{*}{ Total } & \multirow[t]{2}{*}{$\times 2$} & \multirow[t]{2}{*}{ p-value } \\
\hline & Male freq (\%) & Female freq (\%) & & & \\
\hline Urban & 454 (32.95) & 437 (3I.7I) & 891 (64.66) & 0.48 & $0.489 *$ \\
\hline Rural & $255(18.5 \mathrm{I})$ & $232(16.84)$ & 487 (35.34) & 1.32 & $0.25 I^{*}$ \\
\hline TOTAL & 709 (5।.45) & 669 (48.55) & $1378(100.0)$ & & \\
\hline
\end{tabular}

*Not Significant $(p>0.05)$

Table 3. 2 Location by sex Distribution of those that had surgery

\begin{tabular}{|c|c|c|c|c|c|}
\hline \multirow[t]{2}{*}{ Location } & \multicolumn{2}{|l|}{ Sex } & \multirow[t]{2}{*}{ Total } & \multirow[t]{2}{*}{$\mathbf{X} 2$} & \multirow[t]{2}{*}{ p-value } \\
\hline & Male freq (\%) & Female freq (\%) & & & \\
\hline Urban & $153(36.43)$ & $|2|(28.8 \mid)$ & $274(65.24)$ & 5.55 & $0.01 *$ \\
\hline Rural & 91 (2I.67) & $55(13.10)$ & $146(34.76)$ & 10.74 & $0.00 *$ \\
\hline TOTAL & $244(58.10)$ & $176(41.90)$ & $420(100.0)$ & & \\
\hline
\end{tabular}

*Significant $(\mathrm{p}<0.05)$

Table 4. I Time of diagnosis by sex distribution

\begin{tabular}{|c|c|c|c|c|c|}
\hline \multirow[t]{2}{*}{ Period } & \multicolumn{2}{|l|}{ Sex } & \multirow[t]{2}{*}{ Total } & \multirow[t]{2}{*}{$\mathbf{X} 2$} & \multirow[t]{2}{*}{ p-value } \\
\hline & Male freq (\%) & Female freq (\%) & & & \\
\hline Jan-March & $180(13.06)$ & 161 (11.68) & $34 I(24.75)$ & 1.21 & 0.27 \\
\hline April-June & $119(13.43)$ & $91(6.60)$ & $210(15.240$ & 4.04 & $0.04 *$ \\
\hline July-Sep & $185(13.43)$ & 139 (10.09) & $324(23.5 \mathrm{I})$ & 7.4 & $0.00 *$ \\
\hline Oct-Dec & $225(16.33)$ & $278(20.17)$ & $503(36.50)$ & 6.83 & $0.00^{*}$ \\
\hline TOTAL & $709(51.45)$ & $669(48.55)$ & $1378(100.0)$ & & \\
\hline
\end{tabular}

*Significant $(\mathrm{p}<0.05)$

Table 4. 2 Time of surgery by sex distribution

\begin{tabular}{llllll}
\hline Period & Sex & & Total & X2 & p-value \\
& Male freq $(\%)$ & Female freq (\%) & & & \\
\hline Jan-March & $54(12.86)$ & $39(9.29)$ & $93(22.14)$ & 2.72 & 0.09 \\
April-June & $67(15.97)$ & $42(10.0)$ & $109(25.95)$ & 6.59 & $0.0 I^{*}$ \\
July-Sep & $4 I(9.76)$ & $40(9.52)$ & $8 I(19.29)$ & 0.01 & 0.907 \\
Oct-Dec & $82(19.52)$ & $55(13.10)$ & $137(32.62)$ & 6.36 & $0.0 I^{*}$ \\
TOTAL & $244(58.10)$ & $176(41.90)$ & $420(100.0)$ & & \\
\hline
\end{tabular}

*Significant $(p<0.05)$ 


\section{Discussion}

Our national cataract surgical rate of $333 /$ million population $^{7}$ is relatively low when compared to the recommended value of 1000/ surgeon/million. ${ }^{5}$ Barriers to uptake of ophthalmic surgeries have therefore been of interest and as such ophthalmologists need to be aware of them so as to improve. Overall, there was low turnout for surgery compared to the number that presented (1378 that presents and 420 that actually had surgery- i.e. $30.5 \%$ of those that presented eventually had surgery). This agrees with studies carried out in a neighboring state. ${ }^{8}$ The peculiar terrain may be responsible as was shown in that study. Patients from difficult to access areas such as is found in a riverine area as the one under discussion usually find it difficult to access eye care due to the difficulties that arise from transportation, escorts and inherent poverty. It may also mean that either the caregivers are not able or willing to take care of their visually impaired relations or that these patients are getting their care from elsewhere -possibly traditional healers or native doctors who may be involved with couching or use of harmful traditional eye medication. There may therefore be need for collaboration with them (i.e. traditional healers in terms of referral) or a system put in place to improve the quality of eye care in order to make it more attractive and accessible. ${ }^{9}$

Accessibility to where surgical services are is also important as distance and actual location of the service in relation to where the patient is located also influences uptake. ${ }^{10}$ In this study, location whether rural or urban was seen to be important. See Table 3. Higher proportion of those who presented $(65 \%)$ was from urban area and this also reflected in a higher surgical output among urban dwellers of $65 \%$ of total. This shows that proximity to health facility was a positive factor. This further agrees with some studies done which attribute distance to health facility as a factor affecting surgical output. ${ }^{11}$ Socioeconomic status is also a factor as a determinant of uptake. If the cost of the surgery is above the means of the patient in the majority of cases, then the service will not be made use of. In this study, we used the location of residence as an indicator of their socioeconomic status. We found that $35 \%$ of cases who presented were from the rural area while $65 \%$ were from urban area. This had direct impact on total surgical output as $65 \%$ of all operated cases were from urban area while $35 \%$ were from rural area thus reflecting the direct effect of poor socioeconomic status of these rural dwellers on low surgical output.

The time of year was also an indicator of uptake as surgical cases were fewer at certain periods compared with other periods. During the early rainy season (between April and June), a good number of the patients may be engaged with farming and the few that presented probably were very desperate to have surgery because of the gravity of their vision-disabling condition. Despite this, the gender difference was still obvious with more men than women having surgery even within this period. See Tables $4.1 \& 4.2$ Gender access has often been blamed to be one of the barriers to uptake. ${ }^{12}$ In our study, it showed that fewer women had surgery than men and this difference was (statistically) significant $(\mathrm{p}<0.05)$. Other studies have also shown that fewer women have surgeries Late presentation was also a feature that was prominent among the female gender in this study. Of all the females who presented $30 \%$ were elderly while $35.4 \%$ were middle age. However the eventual turn out for surgery was majorly in the elderly age group $(33.7 \%)$ which constitutes the highest percentage as against $50 \%$ in the young adult age group who had surgery in the male gender category.

\section{Conclusion}

In conclusion, gender among other factors is a determinant of surgical uptake here in our hospital. Similar numbers of both sexes as evidenced by the male female ratio of 1:1 present at the eye clinic for surgical related disorders. However more males eventually had surgery when compared with the females even at periods of high activity in secular activities such as the farming period. The location of the women did positively affect this proportion as the proportion of surgical output was higher in urban dwellers in keeping with the higher percentage presentation from the urban area. More elderly women however took up the service when compared with younger ones showing evidence of late presentation. We therefore conclude that the female gender is less advantaged in terms of actual uptake of ophthalmic surgical services and adduce possible reasons to be poor socioeconomic status, long distance to hospital (Rural habitation) and busy periods of the year when potential escorts find it difficult to leave breadwinning to assist their visually disabled relatives who may not have hitherto been involved with contributing to the family's income.

\section{Acknowledgments}

None.

\section{Conflicts of interest}

The authors declare no conflicts of interest.

\section{References}

1. Brilliant GE, Lepkowski JM, Zurita B, et al. Delay in presentation to Hospital For surgery for cong and developmental cataract. Arch Ophthalmol. 1991;109(4).

2. Is empowering women the answer to ending poverty in the developing world? International Development Journalism competition: themes March. 2013.

3. Khandekar R, Mohammed AJ, Negrel AD, et al. The prevalence and causes of blindness in the Sultanate of Oman: the Oman Eye Study (OES). Br J Ophthalmol. 2002;86(9):957-962.

4. Abou-Gareeb I, Lewallen S, Bassett K, et al. Gender and blindness: A meta-analysis of population-based prevalence surveys. Ophthalmic Epidemiol. 2001;8(1):39-56.

5. Geneau R, Lewallen S, Bronsard A, et al. The social and family dynamic behind uptake the uptake of cataract surgery. Br J Ophthalmol. 2005;89(11):1399-1402.

6. World health organization: Deaths by cause, sex and Mortality strata in WHO regions for 2002

7. Mpyet C, Dineen BP, Solomon AW. Cataract surgical coverage and barriers to uptake of cataract surgery in north East Nigeria. $\mathrm{Br} J$ Ophthalmol. 2005;89(8):936-938.

8. Rabiu MM. Cataract blindness and barriers to uptake of cataract surgery in aruralcommu-ty in Northern Nigeria. Br J Ophthalmol. 2001;85(7):776780 .

9. Mypet C, Dineen BP, Solomon AW. Cataract surgical coverage and barrier to uptake of Cataract surgery in leprosy village of north east Nigeria. $\mathrm{Br} J$ Ophthalmol. 2005;89(8):936-938. 
10. Yorston D. High Volume surgery in Developing countries. Eye. 2005;19(10):1083-1089.

11. Bronsard A, Geneau R, Shirima S, et al. Why are children brought late for cataract sugery Qualitative findings From Tanzania. Ophthalmo Epidemio. 2008;15(6):383-388.
12. Melese M, Alemayehu W, Friedlander E, et al. Indirect cost associated with assessing eye care service and barriers to service use in Ethiopia. Trop Med Int Health. 2004;9(3):426-431. 